\title{
Impactos hidroclimáticos de curto prazo no padrão hidrodinâmico de Rio de Estuário Amazônico, Amapá (AP), Brasil
}

O objetivo do trabalho foi analisar o padrão da precipitação, da vazão e do nível de marés semidiurnas na Bacia Hidrográfica do Rio Matapi em 2015 , quando ocorreu o mais intenso fenômeno El Niño dos últimos 100 anos. Para tanto, foram quantificados os índices pluviométricos da área da bacia, monitorada a vazão em uma seção do manancial com um Accustic Doppler Profiller e acompanhada a variação do nível da coluna d'água com um sensor de pressão durante ciclos completos de marés semidiurnas ocorridos nos meses de abril, junho, setembro, outubro e dezembro/2015. Os dados climáticos foram estatisticamente testados para a série temporal de precipitação 1961-2010, bem como comparados com os da literatura. Os resultados confirmaram 2015 como um ano climatologicamente atípico, promovendo descargas líquidas significativamente reduzidas em relação às séries disponíveis (Friedman: a<0,05). Especificamente, o padrão hidrodinâmico foi representado por curvas de histerese bem correlacionadas $(0,76=R 2=0,82)$, que indicam a diferença entre o comportamento dos fluxos de enchente e vazante das marés. Conclui-se que a variação da precipitação resultou da influência do fenômeno El Niño sobre o padrão hidrodinâmico do rio Matapi em 2015 ( $p<0,05$ ) sendo de relevante interesse científico seu monitoramento para fins de gestão hídrica, principalmente em tempos de aquecimento global.

\section{Short-term hydroclimatic impacts on the hydrodynamic pattern of the Amazon Estuary River, Amapá (AP), Brazil}

\begin{abstract}
The objective of the work was to analyze the rainfall pattern, the flow and the level of semidiurnal tides in the Matapi River Basin in 2015, when the most intense El Niño phenomenon of the last 100 years occurred. For that, the rainfall indices of the basin area were quantified, the flow in a section of the spring was monitored with an Accustic Doppler Profiller and the variation of the water column level with a pressure sensor during complete cycles of semidiurn tides occurred in the months of april, june, september, october and december/2015. The climatic data were statistically tested for the 1961-2010 precipitation time series as well as compared with those in the literature. These results confirmed 2015 as a climatologically atypical year, promoting significantly reduced net discharges compared to the available series (Friedman: $\mathrm{a}<0.05)$. Specifically, the hydrodynamic pattern was represented by well correlated hysteresis curves $(0.76=\mathrm{R} 2=0.82$ ) that indicate the difference between flood and tidal flow behavior. It is concluded that the variation in precipitation resulted from the influence of the El Niño phenomenon on the hydrodynamic pattern of the Matapi 2015 river $(p<0.05)$, being of relevant scientific interest its monitoring for water management purposes, especially in times of global warming.
\end{abstract}

Keywords: El Niño phenomenon; Paired statistical analysis; Hydrodynamic series; Hydric balance.

Topic: Meteorologia, Climatologia e Mudanças Climáticas

Reviewed anonymously in the process of blind peer.
Received: 01/01/2021

Approved: 26/01/2021
José da Costa Felix Neto

Universidade Federal do Amapá, Brasil http://lattes.cnpq.br/9493506803702060 ic.felix.neto@hotmail.com

\section{Luany Jaine de Araújo Souza}

Universidade Federal do Amapá, Brasil http://lattes.cnpq.br/2031246919578580

luanyjaine.souza@gmail.com

Carlos Henrique Medeiros de Abreu (iD Universidade Federal do Amapá, Brasil http://lattes.cnpq.br/9009261156099636 http://orcid.org/0000-0003-0904-8791 chmabreu@gmail.com

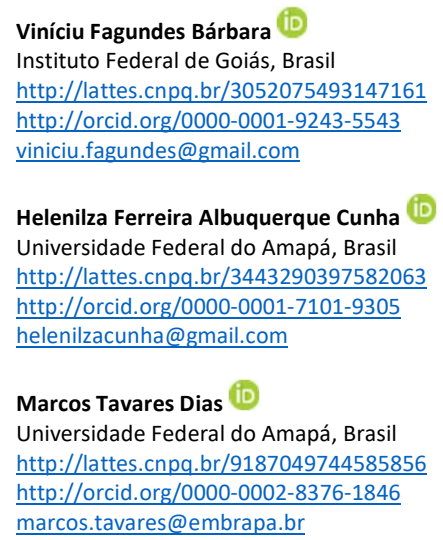

Alan Cavalcanti da Cunha (iD)

Universidade Federal do Amapá, Brasil http://lattes.cnpq.br/2181817533284030 http://orcid.org/0000-0002-1846-9486 alancunha12@gmail.com
Referencing this:

FELIX NETO, J. C.; SOUZA, L. J. A.; ABREU, C. H. M.; BÁRBARA, V. F.; CUNHA, H. F. A.; DIAS, M. T.; CUNHA, A. C.. Impactos hidroclimáticos de curto prazo no padrão hidrodinâmico de Rio de Estuário Amazônico, Amapá (AP), Brasil. Revista Ibero Americana de Ciências Ambientais, v.12, n.1, p.161-179, 2021. DOI: http://doi.org/10.6008/CBPC2179-6858.2021.001.0014 


\section{INTRODUÇÃO}

A floresta amazônica abrange nove países da América do Sul. No Brasil, possui $69 \%$ de sua extensão, cerca de 4,1 milhões de quilômetros quadrados, distribuídos nos estados de Roraima (RR), Rondânia (RO), Acre (AC), Amapá (AP), Pará (PA), Amazonas (AM), Mato Grosso (MT), Maranhão (MA) e Tocantins (TO). Embora o bioma apresente elevada biodiversidade e seja detentor de 1/5 das reservas mundiais de água doce, vem sofrendo degradações crescentes ao longo das décadas de ocupação e exploração humana (EMPRABA, 2015; LATHUILLIERE et al., 2019). Na busca por possíveis soluções para a problemática do aquecimento global, a Amazônia se destaca por atuar como reguladora do clima planetário, especialmente de países como Argentina, Uruguai e Brasil (SOUZA JUNIOR et al., 2009).

No Brasil, grandes assentamentos populacionais se estabeleceram em estuários, ambientes formados por cursos d'água costeiros influenciados pelo oceano e dependentes de uma dinâmica e complexa gama de processos físicos, químicos e biológicos associados. Considerados privilegiados em termos locacionais devido à alta produtividade primária e à elevada disponibilidade hídrica (CUNHA et al., 2013; SORRIBAS et al., 2016; ABREU et al., 2020), estuários também se destacam por fornecerem o serviço ambiental de manutenção de ciclos biogeoquímicos, incluindo-se o hidrológico, que controla fortemente os demais ciclos naturais como o do carbono, nitrogênio, enxofre e fósforo (WARD et al., 2016).

O estuário do rio Amazonas se configura como um trecho de transição hidrológica entre grandes ecossistemas dulcícolas e o ambiente marinho, integrando o continuum amazônico (WARD et al., 2013), diretamente influenciado pelo oceano Atlântico, que interfere na dinâmica da variação do nível fluvial por intermédio de marés semidiurnas de quadratura e sizígia, e que, ao mesmo tempo, também é influenciado pelos índices pluviométricos da Bacia Hidrográfica do Rio Amazonas (BHRA) (CUNHA et al., 2012).

Dentre os fatores capazes de influenciar a dinâmica fluvial de rios estuarinos, a precipitação é um dos principais, pois regula as entradas de água nas bacias hidrográficas via escoamento superficial, interferindo diretamente nas vazões superficiais $(Q)$, influenciando as interações hídricas com o meio terrestre e favorecendo ou limitando as alterações ecológicas locais, tais como as concentrações de cargas orgânicas e inorgânicas, o estoque e a qualidade das águas superficiais e subterrâneas, o transporte de sedimentos, a estrutura da vegetação e a distribuição de peixes, dentre outros (GUEDES et al., 2013; FERREIRA-FERREIRA et al., 2014; LOBÓN-CERVIA et al., 2015).

Segundo Sorribas et al. (2016), aspectos climáticos e hidrodinâmicos estão intimamente associados na região estuarina amazônica, onde há significativa influência nos fluxos de massa e energia (input - output) dos ecossistemas e onde o comportamento fluvial tende a variar mais intensamente nas direções longitudinal e transversal, processos característicos de águas rasas. Naturalmente, as variações hidrodinâmicas favorecem a interação dos corpos hídricos com a biogeoquímica da floresta inundável e a atmosfera, estimulando a alta produtividade primária por intermédio de processos de degradação e trocas de nutrientes e macromoléculas, e da produção de gás carbônico $\left(\mathrm{CO}_{2}\right)$, metano $\left(\mathrm{CH}_{4}\right)$ e vapor de água, gases de efeito estufa (GEE) interdependentes das fases do ciclo hidrológico (WARD et al., 2013; CUNHA et al., 2014; WARD 
et al., 2015).

As ações de origem antrópica associadas ao conjunto das condições ambientais da Amazônia vêm promovendo o surgimento e a intensificação de impactos socioambientais variados na região, resultado de políticas públicas do setor de infraestrutura, saúde e saneamento básico deficientes, e do crescimento populacional desordenado nas zonas urbanas (CUNHA et al., 2003; IMADA et al., 2016). Nesse contexto, é fundamental compreender o comportamento dos vulneráveis ecossistemas hídricos locais, escassamente estudados, principalmente em relação a parâmetros físicos hidrológicos e hidrodinâmicos relevantes, indispensáveis em diagnósticos e prognósticos ambientais que buscam avaliar fragilidades pré-existentes (ROVERSI et al., 2016). De acordo com CONAMA (2005), no âmbito do gerenciamento de recursos hídricos e do entendimento da limnologia de águas continentais, os estuários assumem especial importância na avaliação de impactos ambientais advindos do desenvolvimento humano em regiões tropicais.

Estudos (GONZALEZ et al., 2013; MOREIRA et al., 2018) comprovam que o ecossistema amazônico vem sofrendo consequências negativas e significativas de eventos climáticos atípicos que estão influenciando seu padrão hidrológico, como o El Niño, cujos efeitos repercutem de forma mais acentuada em aspectos hidrodinâmicos e de qualidade das águas de rios estuarinos (SANTOS et al., 2014), haja vista que o fenômeno advém de interações anômalas entre ar e mar que ocorrem no oceano Pacífico Equatorial (GLANTZ, 2015; SERRÃO et al., 2015; SILVA et al., 2016). Nesse sentido, FAO (2016) esclarece que o El Niño do ano de 2015 foi considerado o de maior intensidade do século, tendo sido responsável por grandes perdas agrícolas em vários países da África, Oceania, Ásia e América Latina, ameaçando a segurança alimentar de milhões de pessoas.

De acordo com Souza et al. (2009), o monitoramento hidrodinâmico em estuários amazônicos em condições hidroclimáticas atípicas é capaz de fornecer informações importantes sobre o que poderá ocorrer ao equilíbrio hídrico local se o fenômeno El Niño se tornar mais frequente e persistente num contexto de mudanças climáticas globais, dados que poderão contribuir para o desenvolvimento de novas metodologias de planejamento ambiental voltadas ao gerenciamento de recursos hídricos na região. Entretanto, estudos dessa natureza ainda são escassos (SALAME et al., 2019), notadamente no estado do Amapá (ABREU et al., 2020). Portanto, o presente trabalho objetivou investigar experimentalmente, e a partir de análise estatística inferencial, a ocorrência de impactos climáticos de curto prazo (El Niño 2015) no padrão hidrodinâmico e na variação de marés semidiurnas no rio Matapi, forçadas pelo oceano Atlântico, mediante a correlação de precipitações sobre sua descarga líquida média.

\section{MATERIAIS E MÉTODOS}

\section{Área de Estudo}

O rio Matapi foi escolhido como objeto desta investigação (i) por ser um dos principais afluentes do baixo estuário do rio Amazonas, associado com a existência de significativa expansão urbana de Santana e de uma área portuária integrada a um distrito industrial; (ii) por ser fortemente regido por oscilações do nível 
do oceano e pela pluviometria da BHRA, com comportamento hidrológico dinamicamente complexo e dependente de interações entre a bacia de drenagem e efeitos de marés (CUNHA et al., 2012); (iii) por estar localizado no estado do Amapá, região ainda carente de pesquisas hidrológicas; e (iv) devido ao fato de abrigar antigos agrupamentos populacionais cuja subsistência depende, basicamente, da pesca e da aquicultura (NICOLITE et al., 2009; GONZÁLEZ et al., 2010; PEREIRA et al., 2014). Adicionalmente, apesar de possuir baixa densidade populacional e alta taxa de preservação, a Bacia Hidrográfica do Rio Matapi (BHRM) contém algumas das principais atividades de potencial impacto aos recursos hídricos do Estado (CUNHA et al., 2012).

De acordo com Torres et al. (2006), a BHRM (Figura 1) se localiza na Planície Costeira do Sul do Amapá e é composta por sedimentos arenosos, siltosos e argilitos, formada no período Quaternário, abrangendo os municípios de Santana, Macapá, Mazagão e Porto Grande. O rio Matapi nasce na região central do Estado e escoa no sentido noroeste-sudeste, dividindo os municípios de Santana e Mazagão e desaguando no canal norte do rio Amazonas. Sua área de drenagem de $2.518 \mathrm{~km}^{2}$ é periodicamente inundável nas margens, que servem como amortecimento das marés e fontes de nutrientes (CUNHA et al., 2003). O clima é do tipo tropical, quente e super úmido, com temperaturas que variam de $25^{\circ} \mathrm{C}$ a $27^{\circ} \mathrm{C}$ e precipitação média mensal oscilando entre $50 \mathrm{~mm}$ e $250 \mathrm{~mm}$, com incidência anual superior a $2.400 \mathrm{~mm}$. Possui duas estações sazonais bem definidas, com o período chuvoso compreendido entre os meses de dezembro e junho, com menores valores de temperatura e insolação, e o de estiagem entre julho e novembro (INPE, 2016).

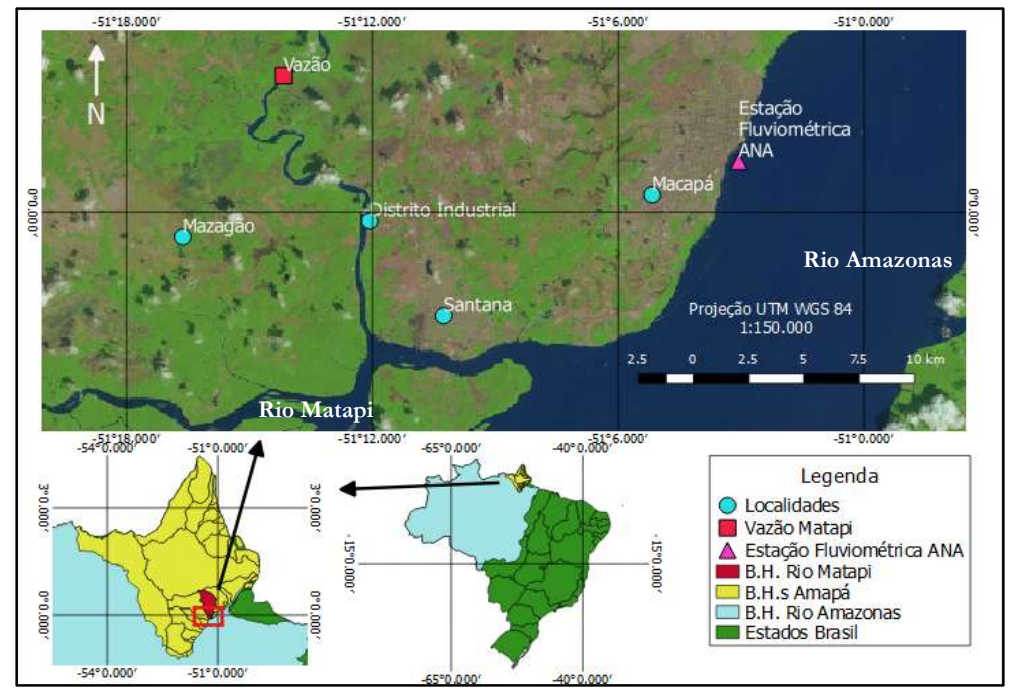

Figura 1: Localização da área de estudo: rio Matapi, afluente do rio Amazonas, situado no estado do Amapá. Fonte: adaptado de ANA (2016).

Na região estuarina do baixo rio Amazonas ocorrem mesomarés semidiurnas que são regidas pela força gravitacional, com maior influência durante as luas cheia e nova e do sol (maré de sizígia), mais perceptível durante o equinócio, que ocorre na segunda quinzena dos meses de março e setembro (CUNHA et al., 2004; TAKIYAMA et al., 2007).

Na presente pesquisa o curso d'água estuarino (rio Matapi) foi definido como 'costeiro influenciado pelo oceano Atlântico/rio Amazonas, dependente de uma complexa gama de processos físicos, químicos e biológicos e suas respectivas interações' (SANTOS et al., 2001; REBOUÇAS et al., 2006; CUNHA et al., 2013). 


\section{Dados Pluviométricos}

Por intermédio do Centro de Previsão do Tempo e Estudos Climáticos (CPTEC), o Instituto Nacional de Pesquisas Espaciais (INPE) ${ }^{1}$ fornece dados de pluviometria. No presente trabalho foi utilizada a série histórica de precipitações médias mensais de 1981 a 2010, e a observada no ano de 2015 para a Região 19, que abrange a BHRM e agrega uma série de dados de várias estações pluviométricas em uma área de $2,5^{\circ} \mathrm{x}$ $2,5^{\circ}$ (latitude e longitude), equivalentes a cerca de $75.625 \mathrm{~km}^{2}$, interpolados mediante o Método de Kriging. Os dados obtidos foram submetidos ao teste não paramétrico de Wilcoxon Pareado e Correlação de Spearman $(p<0,05)$ para comparação das diferenças entre os valores da série histórica e os obtidos em 2015. Como suporte à análise estatística comparativa, também foram utilizados dados referentes a anomalias negativas (El Niño 2015) diárias anuais, com o objetivo de verificar a ocorrência de ausência de chuvas na região do rio Matapi e os consequentes reflexos sobre sua descarga líquida em 2015.

\section{Dados de Descarga Líquida (in loco): Ciclos Completos de Marés}

A seção de monitoramento de descarga líquida foi localizada a $19 \mathrm{~km}$ da foz do rio Matapi (coordenadas $0^{\circ} 3^{\prime} 27,56^{\prime \prime} \mathrm{N}$ e $51^{\circ} 14^{\prime} 11,23^{\prime \prime} \mathrm{O}$; indicada pelo polígono vermelho, Figura 1), em região acessível apenas por via fluvial. As cinco campanhas de campo ocorreram nos dias 24/04/2015 (1a) e 26/06/2015 (2a ), período chuvoso, e em 04/09/2015 (3a); 22/10/2015 (4a) e 04/12/2015 (5aa), estiagem. Foram realizados 167 (abril), 202 (junho), 123 (setembro), 117 (outubro) e 105 (dezembro) perfis de medição na seção de monitoramento. Um Perfilador Doppler Acústico (Acoustic Doppler Profiler - ADP), marca SonTek, modelo RiverSurveyor M9, acoplado em uma embarcação foi utilizado para as campanhas experimentais. Os comandos do ADP foram realizados por intermédio do software RiverSurveyor Live, instalado em um microcomputador portátil acoplado ao aparelho. Os perfis de velocidade e vazão foram conduzidos ao longo de 12:40 h, para completar um ciclo de maré semidiurna.

Os dados de vazão foram comparados com o trabalho de Takiyama et al. (2007), também referente a medições de descarga líquida no rio Matapi, contudo, realizadas em setembro/2001, agosto/2005 e outubro/2006 em seção distante $14 \mathrm{~km}$ a jusante da estabelecida no presente estudo (próximo do ponto denominado 'Distrito Industrial', Figura 1), trecho sem tributários significativos. As comparações foram avaliadas com base na ocorrência de possíveis significâncias entre as variações interanuais de vazão, sendo a referência Takiyama et al. (2007) a única disponível na literatura para este objetivo. Finalmente, os resultados foram submetidos ao teste não paramétrico de Friedman, que identifica possíveis diferenças significativas $(p<0,05)$ entre as precipitações ou variações interanuais da descarga líquida no rio Matapi.

\section{Dados do Nível da Água (in loco)}

As variações do nível da água foram obtidas ao mesmo tempo em que as medições hidrodinâmicas (ADP). Para tanto, empregou-se um sensor de pressão da marca Onset, modelo HOBO U20, instalado próximo

\footnotetext{
${ }^{1}$ www.cptec.inpe.br
} 
da seção de medida de descarga líquida, mas sem um nível de referência. O software HOBOware serviu como suporte ao procedimento de coleta automática da pressão absoluta com número fixo de medições e intervalos definidos com base no tempo total de obtenção dos dados ( $\approx 1$ minuto), e durante todo o ciclo de maré semidiurna $(12: 40 \mathrm{~h})$.

O sensor de pressão foi instalado em um suporte fixo na margem do rio Matapi, próximo ao ponto de medição de descarga líquida (Figura 1), de forma que o sensor ficasse acima do nível da coluna d'água durante a vazante da maré. Os dados obtidos foram correlacionados com os de variação do nível da água do mesmo período, disponibilizados pela Agência Nacional de Águas (ANA) no endereço eletrônico² para a estação de Macapá, código 19500000, localizada no rio Amazonas (ponto 'Estação Fluviométrica ANA'; Figura 1), situada a $41 \mathrm{~km}$ de distância da seção de estudo do rio Matapi (coordenadas $0^{\circ} 1^{\prime} 19,97^{\prime \prime} \mathrm{N}$ e $51^{\circ} 3^{\prime} 0,51^{\prime \prime}$ O).

Os dados foram organizados em planilhas posteriormente disponibilizadas para as análises estatísticas $(p<0,05)$. Curvas de regressões lineares foram obtidas a fim de verificar possíveis correlações entre a variação do nível da água do rio Matapi e o datum de referência do rio Amazonas (histereses). A curva de histerese é indicativa do comportamento da curva de maré, tanto ascendente (enchente: sinal negativo) quanto descendente (vazante: sinal positivo), assumindo o formato de elipse.

\section{RESULTADOS E DISCUSSÃO}

A Figura 2a apresenta o comportamento pluviométrico anormal de 2015 (linha vermelha) em relação à média climatológica histórica dos intervalos interquartílicos (período de 1981 a 2010; linha preta). A Figura $2 \mathrm{~b}$ ilustra a correlação e os desvios médios mensais observados entre os conjuntos de dados dos diferentes períodos, sugerindo o efeito da anomalia negativa da precipitação acumulada na maior parte do ano ( $\approx-50$ $\mathrm{mm}$ ) nos meses de janeiro (1), abril (4), julho (7), agosto (8), setembro (9), outubro (10), novembro (11) e dezembro (12), exceto o mês de junho (6), que apresentou anomalia positiva, e valores extremos, como o ocorrido em março (3) ( $\approx-150 \mathrm{~mm}$ ), de acordo com a análise das diferenças. Adicionalmente, a Figura $2 \mathrm{~b}$ demonstra que houve significativa correlação (covariância) entre ambas as séries $\left(R^{2}=0,88 ; p<0,05\right.$ ), sugerindo um padrão comportamental bem definido da precipitação, apesar do ano climático de 2015 ter sido atípico (deslocamento da curva vermelha para baixo).

A comparação entre as duas curvas da Figura 2a sugere diferenças consideráveis entre os conjuntos de dados (Wilcoxon pareado, $p<0,05$ ). Assim, com base neste critério, se aceita a hipótese de comportamento hidroclimatológico atípico na área de influência na BHRM (Região 19), provocada pela redução das precipitações no ano de 2015, período muito seco em relação à média histórica (CUNHA et al., 2018).

Na Tabela 1 são apresentadas as informações das cinco campanhas de campo realizadas no rio Matapi ao longo do ano de 2015, bem como os dados dos parâmetros hidrodinâmicos referentes ás

${ }^{2}$ http://gestorpcd.ana.gov.br/ 
mensurações feitas com o ADP, todas executadas durante marés lunares de quadratura.
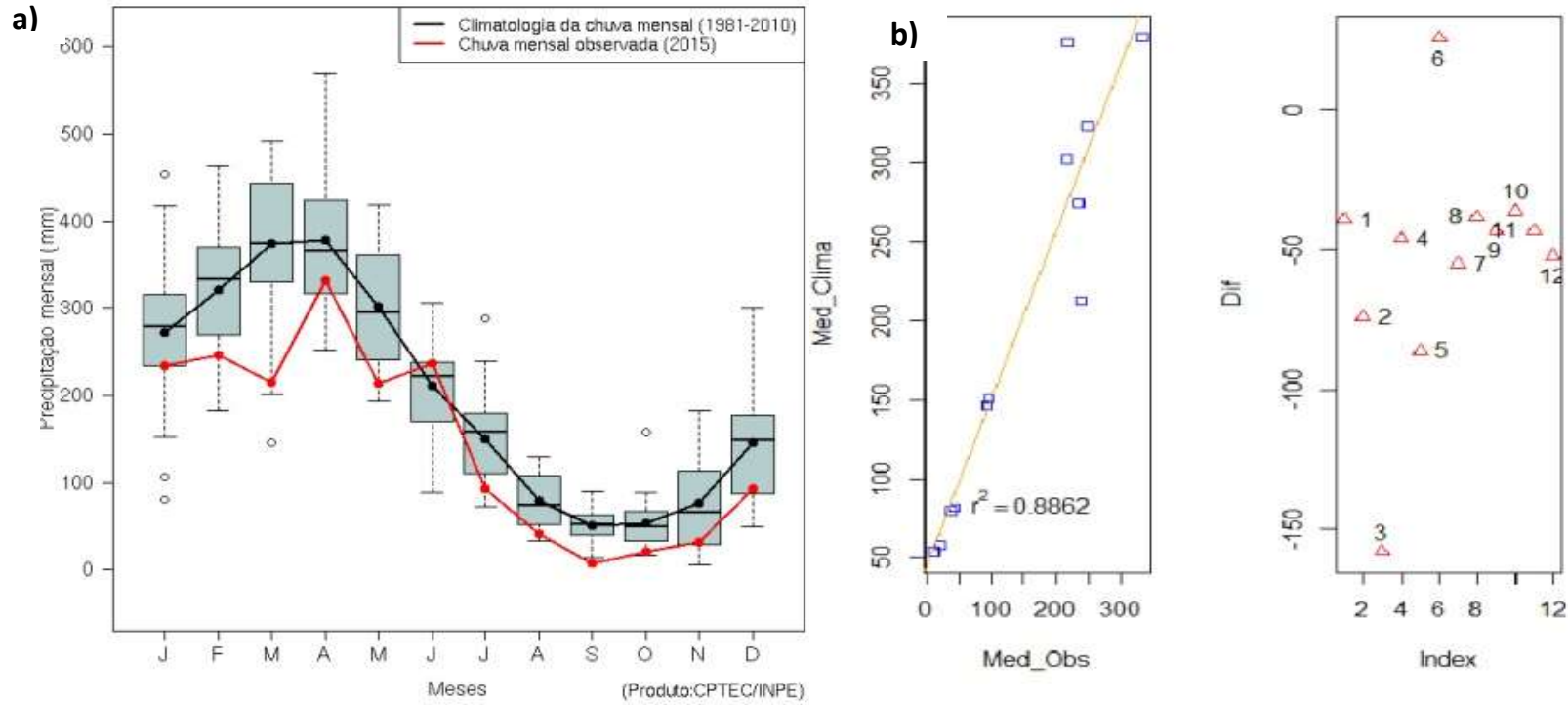

Figura 2: a) Climatologia da chuva mensal [(período de 1981-2010) e a observada em 2015] para a Região 19. b) Correlação entre os dados de precipitação, incluindo os desvios em relação às respectivas médias mensais (os números indicam o mês de observação). Fonte: INPE (2016).

Tabela 1: Informações referentes às campanhas de campo realizadas no rio Matapi durante o ano de 2015, e resultados hidrodinâmicos.

\begin{tabular}{|c|c|c|c|c|c|}
\hline \multirow[b]{2}{*}{ Informações de campo } & \multicolumn{5}{|c|}{ Data da campanha de campo } \\
\hline & $\begin{array}{l}1 \text { a } \\
(24 / 04 / 15)\end{array}$ & $\begin{array}{l}2 \mathrm{a} \\
(26 / 06 / 15)\end{array}$ & $\begin{array}{l}3 \text { a } \\
(04 / 09 / 15)\end{array}$ & $\begin{array}{l}4 \text { a } \\
(22 / 10 / 15)\end{array}$ & $\begin{array}{l}5 \mathrm{a} \\
(04 / 12 / 15)\end{array}$ \\
\hline Número de perfis percorridos (un.) & 167 & 202 & 123 & 117 & 105 \\
\hline Tempo de vazante $(\mathrm{h})$ & 08:04 & 08:30 & 07:40 & $07: 24$ & $07: 22$ \\
\hline Tempo de enchente $(\mathrm{h})$ & 04:26 & 04:00 & 04:50 & 05:06 & 05:08 \\
\hline Precipitação média mensal (mm) & 340 & 230 & 8 & 12 & 90 \\
\hline $\begin{array}{l}\text { Parâmetros hidrodinâmicos } \\
\text { (rio Matapi) }\end{array}$ & $\begin{array}{l}\text { 1a } \\
(24 / 04 / 15)\end{array}$ & $\begin{array}{l}2 \mathrm{a} \\
(26 / 06 / 15)\end{array}$ & $\begin{array}{l}3 \mathrm{a} \\
(04 / 09 / 15)\end{array}$ & $\begin{array}{l}4^{\mathbf{a}} \\
(22 / 10 / 15)\end{array}$ & $\begin{array}{l}5 \mathrm{a} \\
(04 / 12 / 15)\end{array}$ \\
\hline$Q_{\text {total }}\left(m^{3} \cdot s^{-1}\right)$ & $1.121,1$ & 976,0 & $1.285,1$ & 961,4 & 906,5 \\
\hline$Q_{\text {máx (vazante) }}\left(m^{3} \cdot s^{-1}\right)$ & 686,5 & 436,5 & 477,0 & 348,6 & 338,3 \\
\hline$Q_{\text {máx (enchente) }}\left(\mathrm{m}^{3} \cdot \mathrm{s}^{-1}\right)^{*}$ & $-434,6$ & $-539,5$ & $-808,1$ & $-612,8$ & $-568,2$ \\
\hline $\mathrm{V}_{\text {máx (vazante) }}\left(\mathrm{m} \cdot \mathrm{s}^{-1}\right)$ & 0,9 & 0,6 & 0,7 & 0,5 & 0,5 \\
\hline$V_{\text {máx (enchente) }}\left(m \cdot s^{-1}\right)^{*}$ & $-0,4$ & $-0,6$ & $-0,9$ & $-0,8$ & $-0,8$ \\
\hline Maré & \multicolumn{5}{|l|}{ Quadratura } \\
\hline
\end{tabular}

$(*)$ Valores negativos dos parâmetros hidrodinâmicos indicam maré de enchente, no sentido foz-montante. Q: vazão. V: velocidade.

Os resultados da Tabela 1 sugerem que a duração média da maré vazante foi de 7:48 h, enquanto da maré enchente foi de 4:42 h, evidenciando que a vazante foi o fluxo majoritário e natural na seção de medida na BHRM nos meses de setembro, outubro e dezembro/2015. Adicionalmente, o intervalo temporal da maré vazante foi maior nos primeiros meses observados (abril e junho/2015), provavelmente devido à forte influência do rio Amazonas (barreira hidráulica), cujo efeito tende a diminuir ao longo do ano em virtude do decréscimo hídrico que ocorre no período de estiagem. Esse resultado pode ser explicado pelo menor escoamento hídrico superficial associado à dependência de recarga pelo lençol freático ao longo do ano, resultado da interação entre a bacia hidrográfica e o estuário (CUNHA et al., 2011).

O intervalo temporal médio da maré no período seco (setembro, outubro e dezembro/2015; Tabela 1) foi de $7: 28 \mathrm{~h}$ para a maré vazante, e de $5: 01 \mathrm{~h}$ para a maré enchente, diferindo modestamente dos resultados obtidos por Takiyama et al. (2007) também para o rio Matapi, que encontraram para os meses de 
setembro/2001, agosto/2005 e outubro/2006 os valores médios de 7:51 h para a maré vazante e de 4:38 h para a maré enchente. Nicolite et al. (2009), avaliando a oscilação do nível de água e a co-oscilação da maré astronômica no baixo estuário do rio Paraíba do Sul, estado do Rio de Janeiro (RJ), constataram que as assimetrias no tempo de subida e descida da maré foram maiores na quadratura do que na sizígia, devido às amplitudes de maré normalmente menores na quadratura, o que torna relativamente maior o papel da descarga da bacia hidrográfica.

A Figura 3a-b apresenta o comportamento típico das descargas líquidas (Figura 3a) e das velocidades absolutas (Figura 3b) observadas no rio Matapi ao longo dos ciclos de marés semidiurnas de 2015 investigados. Os valores negativos indicam maré enchente, os positivos a vazante, e os nulos a inversão da maré.

a)

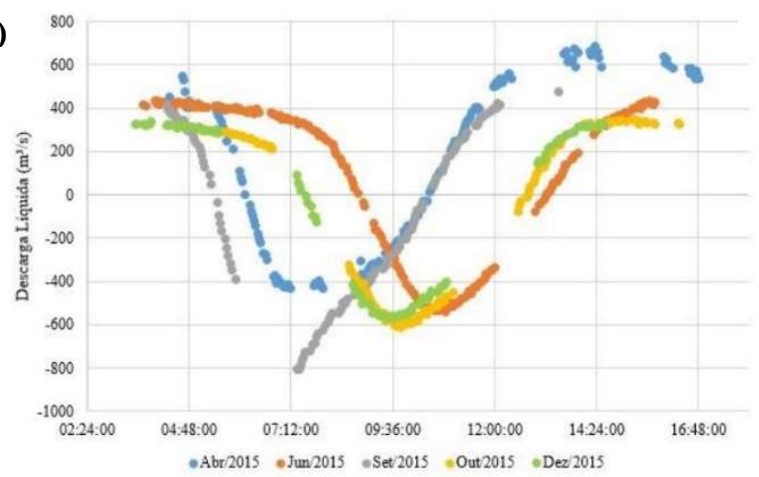

b)

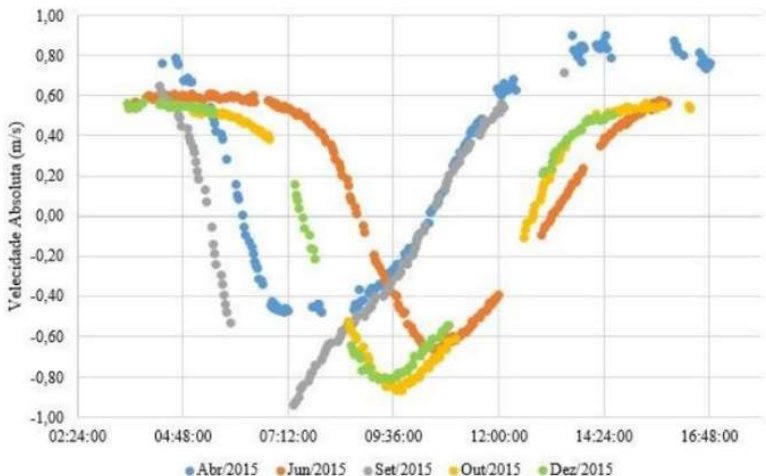

Figura 3: a) Descargas líquidas (vazões) e b) velocidades absolutas do rio Matapi medidos durante os ciclos de marés semidiurnas observadas nos meses de abril, junho, setembro, outubro e dezembro de 2015.

De acordo com a Tabela 1 e a Figura 3, o mês de abril/15 foi o que apresentou a maior descarga líquida $\left[-434,6 \leq \mathrm{Q} \leq 686,5 \mathrm{~m}^{3} \cdot \mathrm{s}^{-1}\right]$, explicada pela incidência pluviométrica de $340 \mathrm{~mm}$ (média), a maior do período de monções. Esse fato teve implicações diretas no fluxo da maré vazante, maior que a enchente apenas neste período, evidenciando a influência das chuvas no escoamento superficial e na hidrodinâmica na bacia do rio Matapi. No mês de junho a vazão variou $-539,5 \mathrm{~m}^{3} \cdot \mathrm{s}^{-1}$ a $436,5 \mathrm{~m}^{3} \cdot \mathrm{s}^{-1}$, representando o período de transição chuvoso-seco, com precipitação média de $230 \mathrm{~mm}$, bem maior do que a dos meses seguintes, única diferença positiva em relação à climatologia. Especificamente, setembro apresentou a já citada influência do equinócio, com um intervalo de vazão oscilando de $-808,1 \mathrm{~m}^{3} \cdot \mathrm{s}^{-1}$ a $477,0 \mathrm{~m}^{3} \cdot \mathrm{s}^{-1}$, e o maior valor de descarga líquida total $\left(1.285,1 \mathrm{~m}^{3} \cdot \mathrm{s}^{-1}\right)$ superando o mês de abril, apesar de apresentar apenas $8 \mathrm{~mm}$ de precipitação média. Em outubro foi estimada a descarga líquida de $\left[-612,8 \leq \mathrm{Q} \leq 348,6 \mathrm{~m}^{3} \cdot \mathrm{s}^{-1}\right]$, e precipitação média de $12 \mathrm{~mm}$, pouco maior do que setembro, contudo, sem a influência da oscilação oceânica provocada pelo equinócio. Em dezembro, final do período seco, foram registrados os menores valores de descarga líquida observados $\left[-568,2 \leq \mathrm{Q} \leq 338,3 \mathrm{~m}^{3} \cdot \mathrm{s}^{-1}\right]$, sendo possível deduzir que nesse período houveram os níveis de coluna d'água mais baixos devido ao término da estação de estiagem.

Em relação à velocidade, Kjerfve et al. (1988) esclarecem que durante um ciclo de maré ocorre forte oscilação desse parâmetro nos rios formadores de estuários, sendo este um elemento fundamental para a detecção de variações no aporte de sedimentos, na ciclagem interna e nos padrões de erosão e sedimentação 
associados aos ciclos de maré, por exemplo. Nesse sentido, abril/15 foi o único período em que o valor obtido referente à maré vazante foi maior que o da enchente $\left[-0,4 \leq \mathrm{V} \leq 0,9 \mathrm{~m} \cdot \mathrm{s}^{-1}\right]$, enquanto que nos demais meses foi observada maior intensidade de velocidade durante a maré enchente. Isto certamente é resultado de um maior avanço das águas do rio Amazonas sobre o rio Matapi, influenciando suas características físicas e, muito provavelmente, químicas e biológicas.

Alcântara (2007) explica que quando a maré exerce pressão significativa sobre a corrente de água doce do sistema hídrico afluente, faz com que parte dessa fração seja misturada com a água do mar adjacente, e outra deslocada para montante, caracterizando a enchente que, no caso do rio Matapi, demonstra ser mais intensa no período de seca. De acordo com Friedrichs (2010), a prevalência de enchente é comum em estuários dominados por variações na profundidade do canal ao longo de um ciclo de maré, ao invés da largura, em virtude da presença de planícies de maré, o que provavelmente é o caso do rio Matapi. Por sua vez, Mao et al. (2004) destacam que a assimetria de marés tende a exercer efeitos na evolução geológica de estuários rasos, sendo que aqueles onde ocorre a dominância de enchente podem ser incapazes de efetivamente liberar sedimentos para fora do sistema.

Embora exista o efeito do amortecimento espacial das marés, Nunes Filho (2016) não encontrou diferenças significativas na amplitude deste, mesmo a uma distância de 67 km entre dois pontos de medição situados no rio Amazonas, assim como Souza (2016), que também estudou o rio Matapi. Neste aspecto, na presente investigação, sugere-se que não há alteração relevante na descarga líquida medida entre dois pontos relativamente próximos, como por exemplo, a seção de monitoramento estabelecida neste estudo e a de Takiyama et al. (2007), distante $14,5 \mathrm{~km}$ a jusante, no mesmo manancial (rio Matapi), trecho onde não ocorrem acréscimos de hídricos de afluentes contribuintes, sendo possível comparar dados entre ambos os trabalhos neste trecho, como já informado.

Takiyama et al. (2007) realizaram três campanhas de mediação de descarga líquida em um trecho do rio Matapi próximo ao Distrito Industrial de Santana nos meses de setembro/2001, agosto/2005 e outubro/2006, tendo comprovado que em setembro e agosto houve relativa influência da lua (maré de sizígia que antecedeu à de quadratura), favorecendo o aumento da vazão em relação à maré de quadratura. Contudo, o real efeito na hidrodinâmica do rio Matapi ainda é desconhecido, não sendo possível observar precisamente a diferença entre esses dois períodos, haja vista que todas as campanhas de campo desta pesquisa foram desenvolvidas também durante marés de quadratura, para evitar erros com as medidas de quadratura e sizígia.

Com base no critério de déficit hídrico e visando identificar anomalias negativas provocadas pelo fenômeno El Niño, as Figuras 4a-f e 5 (INPE, 2016) ilustram os dados das precipitações diárias acumuladas em diferentes anos-referência para a Região 19: (i) 2015, quando foram realizadas as campanhas de campo referentes ao presente trabalho, e 2014, ano anterior, selecionado para fins comparativos; e (ii) anos em que ocorreram as medições de Takiyama et al. (2007) (2001, 2005 e 2006) e anteriores a estes (2000 e 2004), também para fins comparativos. 

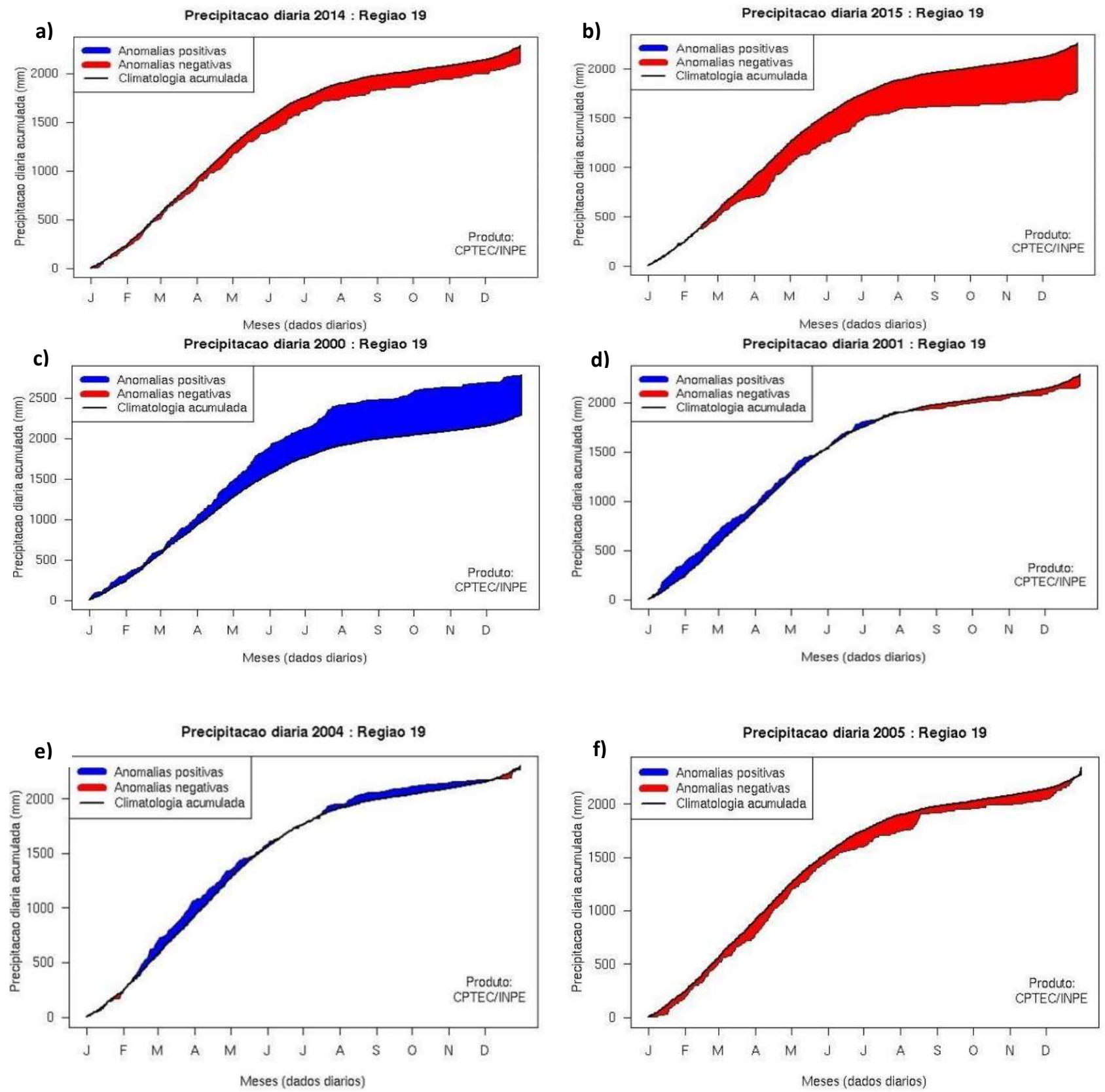

Figura 4: Precipitações diárias históricas acumuladas, representado a ocorrência de anomalias climáticas negativas e positivas na Região 19 nos anos de a) 2014; b) 2015; c) 2000; d) 2001; e) 2004; f) 2005. Fonte: INPE (2016).

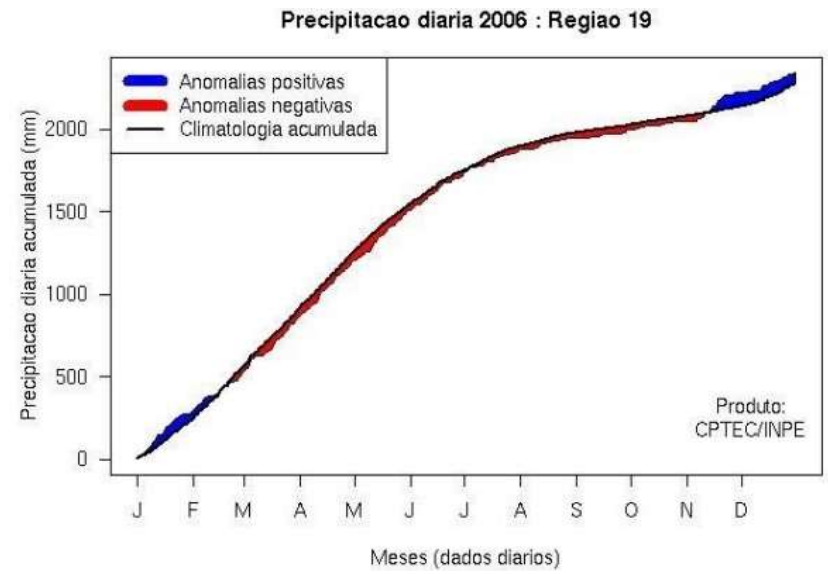

Figura 5: Precipitações diárias históricas acumuladas, representado a ocorrência de anomalias climáticas negativas e positivas na Região 19 no ano de 2016. Fonte: INPE (2016).

Nas Figuras 4a e 4b, referentes aos anos de 2014 e 2015, respectivamente, o aumento da distância 
da linha preta representa a diferença média histórica acumulada, ilustrando a elevação de anomalias negativas (em vermelho) de janeiro a dezembro em ambos os anos. A Figura 4a indica anomalias negativas que começam em abril, aproximadamente, e se estendem para o restante do ano, mesmo comportamento observado em 2015 (Figura 4b), contudo, de forma mais acentuada entre abril e julho, também se acentuando progressivamente até dezembro. Estes fatos evidenciam que já havia um déficit no balanço hídrico da BHRM em 2015 referente às anomalias negativas de 2014, sem nenhum acúmulo que compensasse essa perda, e com um aumento substancialmente maior em 2015, sendo possível afirmar que neste último ano a pluviosidade sofreu diminuição significativa devido à ocorrência do El Niño intenso.

De acordo com a Figura 4c, verifica-se que em 2000 ocorreram anomalias positivas em relação à climatologia histórica na BHRM, principalmente a partir de junho. Por sua vez, o ano de 2001 (Figura 4d) não apresentou anomalias relevantes, podendo ser considerado como normal, tendo em vista que o acúmulo anterior não influenciou a hidrodinâmica em setembro/2001 (mês contemplado na pesquisa de TAKIYAMA et al., 2007), dada a relativamente pequena extensão da bacia. Adicionalmente, em 2004 (Figura 4e) também não ocorreram anomalias significativas em relação à climatologia histórica, mas apenas variações positivas pouco relevantes que duraram a maior parte do ano, ao contrário do observado por Takiyama et al. (2007) em agosto/2005 (Figura 4f), contudo, em intensidade baixa e sem significância estatística. Por fim, em 2006 (Figura 5) não houve anomalia considerável em relação à climatologia histórica, observando-se um padrão completamente normal.

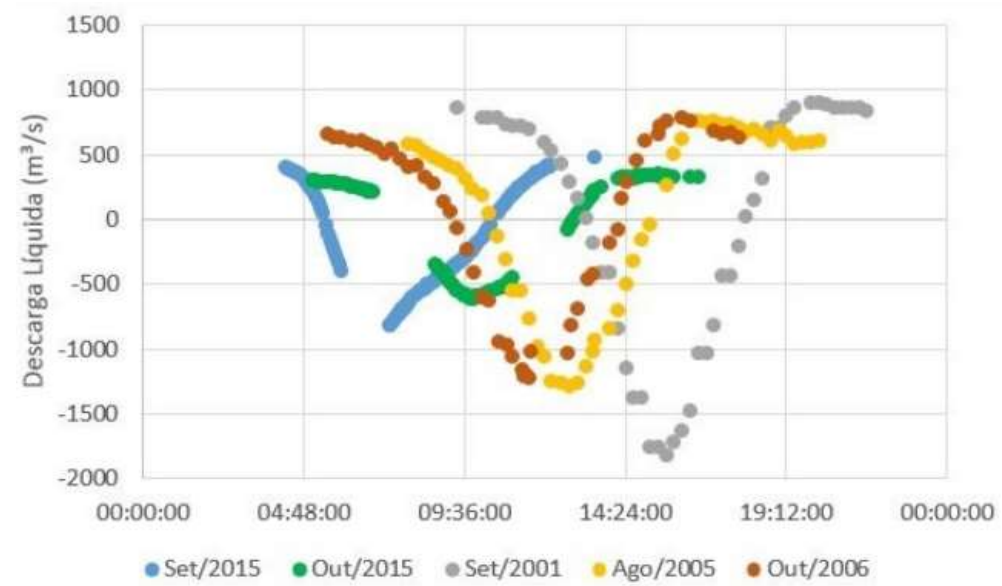

Figura 6: Correlação dos dados de vazão do rio Matapi no período de estiagem mensurados pelos autores em setembro e outubro/2015, com os obtidos por Takiyama et al. (2007) em setembro/2001, agosto/2005 e outubro/2006. Fonte: Takiyama et al. (2007).

No geral, observa-se que os resultados de vazão do rio Matapi obtidos no presente estudo para o período de estiagem - setembro/2015 (3a campanha de campo) e outubro/2015 (4a campanha de campo) $(p<0,05)$, quando as marés vazantes atingiram valores de $\left[-808,1<Q<477,0 \mathrm{~m}^{3} \cdot \mathrm{s}^{-1}\right]$ e $\left[-612,8<Q<348,6 \mathrm{~m}^{3} \cdot \mathrm{s}^{-}\right.$ ${ }^{1}$ ], respectivamente - diferem de forma significativa dos encontrados por Takiyama et al. (2007): [-1.820,0 $\left.<\mathrm{Q}<875,0 \mathrm{~m}^{3} \mathrm{~s}^{-1}\right]$ para setembro/2001; [-1.310,0 $\left.<\mathrm{Q}<769,0 \mathrm{~m}^{3} \cdot \mathrm{s}^{-1}\right]$ para agosto/2005 e $[-1.210,0<\mathrm{Q}<763,0$ $\left.\mathrm{m}^{3} \cdot \mathrm{s}^{-1}\right]$ para outubro/2006, conforme pode ser visualizado na Figura 6. Verifica-se, ainda, que mesmo para o mês de setembro/2015, sob influência do equinócio, os dados de descarga líquida foram significativamente 
menores, com a maré enchente correspondendo a apenas cerca de $50 \%$ dos valores observados por Takiyama et al. (2007).

As diferentes medianas ilustradas na Figura 6 indicam significativa variação entre as vazões das quatro comparações interanuais ( $p=0,02556$ ): anos 2001, 2005, 2006 e 2015. Contudo, quando consideradas apenas as médias dos anos de 2001, 2005 e 2006, o resultado não foi significativo ( $p=0,2466)$, isto é, não há diferenças relevantes entre as vazões se considerados apenas os referidos anos. Todavia, quando os dados de 2015 são introduzidos na análise, o resultado é oposto e significativo $(p<0,05)$, possibilitando inferir, com base neste critério, que a diferença por comparação entre as quatro medidas interanuais foi resultado justamente das mensurações de vazão de 2015. Portanto, como não há indícios de diferenças significativas entre os demais anos (2001, 2005 e 2006), as medições feitas em 2015 indicam que a diminuição da pluviosidade provavelmente ocorreu devido ao fenômeno El Niño, também constatado em 2005, porém, sem interferência significativa na pluviosidade, como já descrito. Outra inferência possível na Figura 6 é que a ocorrência do El Niño no ano de 2015 também deve ter influenciado a variação e a amplitude da descarga líquida do rio Matapi, diminuindo sua vazão em torno de 50\% em relação aos valores médios observados em períodos considerados como climatologicamente normais (2001, 2005 e 2006), observação também feita por Cunha et al. (2018) em estudo desenvolvido em vários lagos do estuário amazônico.

Complementarmente às medidas de vazão no rio Matapi, foi analisado o padrão de variação dos níveis de marés medidos pelo sistema de monitoramento oficial próximo, localizado no rio Amazonas (ANA, 2016). O resultado está ilustrado na Figura 7a-d, cujas comparações entre dados resultaram na formação de gráficos do tipo elipse (histerese), que representam o efeito real da dinâmica do escoamento em relação ao referencial conhecido (ANA, 2016). Assim, visando avaliar diretamente as flutuações médias (independente do sentido dos fluxos) entre ambas as seções de medida, elaborou-se uma regressão linear simples que desconsiderou propositalmente os efeitos de ascendência e descendência da maré. Como resultado, os valores obtidos variaram entre o intervalo $\left[0,87<R^{2}<0,91\right]$, sugerindo relativamente alta correlação (covariância) entre ambas.

Especificamente, em junho (Figura 7a) observa-se que o coeficiente angular da linha de regressão média $\left\{Y_{(\text {Matapi) }} \sim X_{\text {(Amazonas) }}\right\}$ foi de $0,85\left(R^{2}=0,82\right)$, resultando no melhor ajuste dentre todos os demais meses analisados (setembro, outubro e dezembro); desse modo, a elipse se apresentou mais estreita, com maior proximidade entre as curvas de ascendência e descendência dos fluxos, demonstrando que o comportamento da maré ascendente e descendente no período foi mais próximo que nos demais. Em setembro, constata-se que o coeficiente angular da linha de regressão média $\left\{Y_{\text {(Matapi) }} \sim X_{(\text {Amazonas })}\right\}$ foi de 0,74 $\left(R^{2}=0,76\right)$, ou seja, um pouco menor ao longo de todo o ano, resultando no ajuste menos significativo dentre todos os demais meses. Neste período, a elipse se apresentou mais larga, com maior distância entre as curvas de ascendência e descendência das correntes, significando que o comportamento das marés foi mais distinto que nos outros meses.

Em junho (Figura 7a), o coeficiente angular da linha de regressão média apresentou amplitude média de 1,93 m, resultando no melhor ajuste dentre todos outros. Em setembro (Figura 7b), observa-se que o 
coeficiente foi menor ao longo de todo o ano, com amplitude média de 2,45 m, resultando no pior ajuste dentre todos os demais meses. Em outubro (Figura 7c), o coeficiente angular foi de $0,83\left(R^{2}=0,78\right)$, com uma amplitude média de 1,91 m, resultando em um valor um pouco menor do que o de setembro. Finalmente, em dezembro (Figura 7d), observa-se que o valor foi o maior dentre os estudados, de $0,81\left(R^{2}=0,78\right)$, com amplitude média de 1,88 m, resultando em ajuste mediano quando comparado aos demais meses.

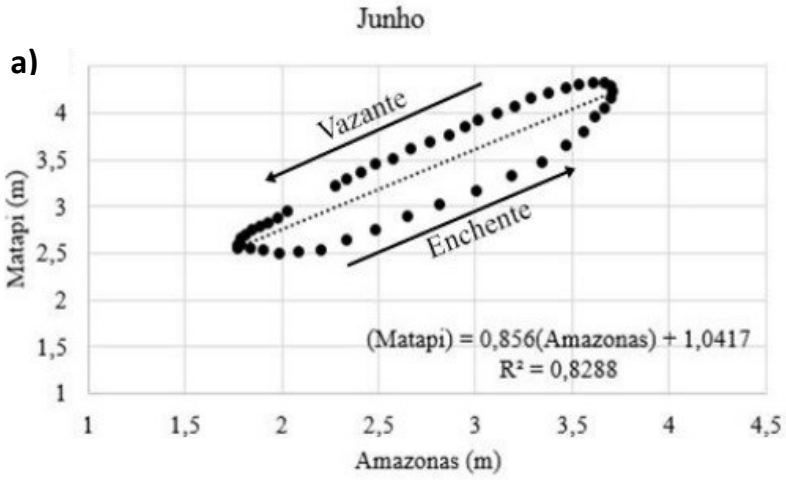

Dezembro

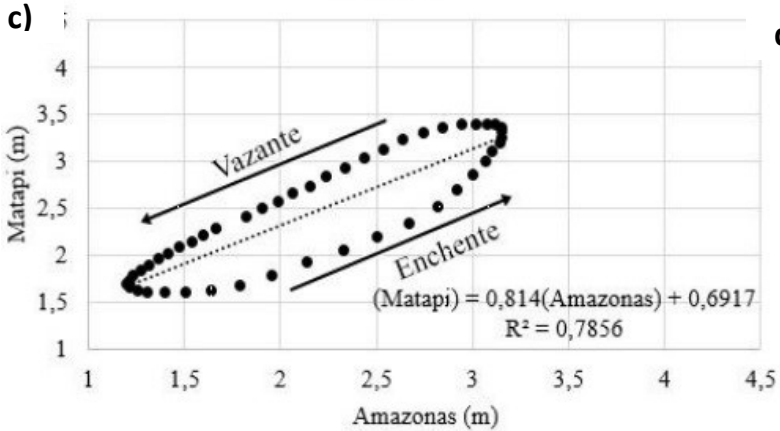

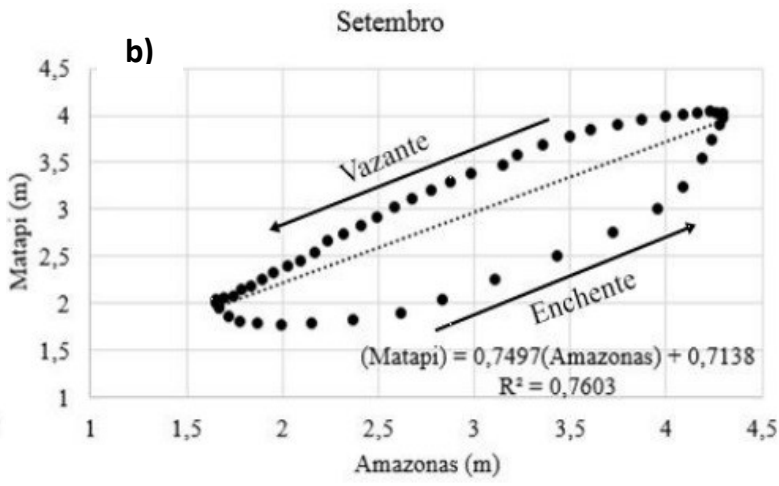

Outubro

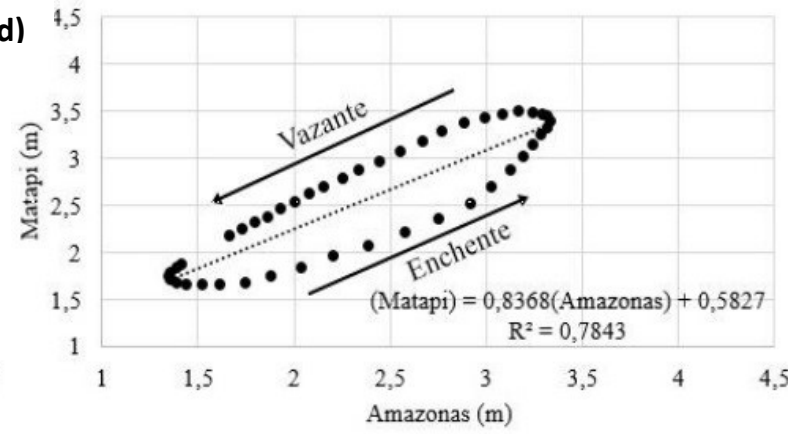

Figura 7: Correlações entre as variações dos níveis da coluna d'água do rio Matapi com as do rio Amazonas, considerando-se conjuntamente ambos os sentidos dos fluxos (enchente e vazante) nos meses de a) junho, b) setembro, c) outubro e d) dezembro/2015. Fonte: ANA (2016).

Na Tabela 2 é possível verificar que as diferenças dos parâmetros estatísticos descritivos da variação do sensor de pressão (Matapi e Amazonas) são relativamente pequenas, sendo que o maior valor observado foi o referente ao mês de setembro $(0,38 \mathrm{~m})$.

Tabela 2: Valores máximos, mínimos e de amplitude do nível da água nos rios Matapi (M) e Amazonas (A). Como os valores $\left({ }^{*}\right)$ do Matapi não têm ponto de referência, os máximos e mínimos mensais não podem ser comparados entre si, mas apenas a amplitude.

\begin{tabular}{|c|c|c|c|c|c|c|c|c|c|c|}
\hline \multirow{2}{*}{ Parâmetro } & \multicolumn{2}{|c|}{ Abril/15 } & \multicolumn{2}{|c|}{ Junho/15 } & \multicolumn{2}{|c|}{ Setembro/15 } & \multicolumn{2}{|c|}{ Outubro/15 } & \multicolumn{2}{|c|}{ Dezembro/15 } \\
\hline & $M$ & A & M & A & M & A & M & A & M & A \\
\hline Máximo (m) & - & 4,60 & $4,30^{*}$ & 3,71 & $4,02^{*}$ & 4,30 & $3,48^{*}$ & 3,34 & $3,39^{*}$ & 3,16 \\
\hline Mínimo $(m)$ & - & 1,70 & $2,28^{*}$ & 1,78 & $1,76^{*}$ & 1,66 & $1,64^{*}$ & 1,35 & $1,58^{*}$ & 1,20 \\
\hline Amplitude $(\mathrm{m})$ & - & 2,90 & 1,92 & 1,93 & 2,26 & 2,64 & 1,84 & 1,99 & 1,81 & 1,96 \\
\hline Diferença entre as amplitudes (m) & \multicolumn{2}{|l|}{-} & \multicolumn{2}{|l|}{0,01} & \multicolumn{2}{|l|}{0,38} & \multicolumn{2}{|l|}{0,15} & \multicolumn{2}{|l|}{0,15} \\
\hline
\end{tabular}

M: Matapi. A: Amazonas.

Os resultados obtidos com o presente estudo possibilitam algumas reflexões e comparações com a literatura. Kjerfve et al. (1982) afirmam que a hidrodinâmica de um estuário é o resultado da interação entre a morfologia da bacia, o aporte fluvial e o regime de marés, sendo que a elevada variação temporal e espacial desses forçantes e dos processos a eles associados torna a pesquisa dos padrões de circulação e distribuição de propriedades nos sistemas estuarinos bastante complexa. Miranda et al. (2002) e Torres et al. (2006) 
complementam que esses ambientes também são diretamente influenciados pelos ventos e variações do nível médio do mar, e por processos de pequena e média variação temporal, como os erosivos e deposicionais decorrentes da atuação das ondas e das correntes costeiras. Adicionalmente, Miranda et al. (2002) e Pugh (2004) destacam que a descarga de água que chega a um estuário é originada da bacia de drenagem a qual o rio contribuinte pertence, sendo que sua taxa também depende das condições climáticas locais, das características do solo, da cobertura vegetal, da evapotranspiração e da ocupação antropogênica. Segundo Godin (1991) e Parker (1991), contudo, a maré tem influência dominante na dinâmica de estuários devido à sua capacidade de se propagar para dentro do continente (em direção aos rios afluentes), fenômeno gerado pela fricção do fundo e dos contornos terrestres com a geometria do estuário, capazes de resultar em ondas de maré com diferentes amplitudes e na transferência de energia a partir das constituintes harmônicas fundamentais que formam a maré superficial astronômica, favorecendo a ocorrência de frequências harmônicas mais altas ou mais baixas que constituem as correntes dominantes de marés de vazante ou enchente.

De acordo com Nicolite et al. (2009) e Roversi et al. (2016), a variação da coluna d'água ocorre, principalmente, devido à influência de forças astronômicas e da pluviosidade. Na região de mesomarés do rio Matapi, no período chuvoso amazônico, os níveis das águas dos rios locais podem subir até 4,0 m, alcançando cotas máximas nos períodos de enchente, notadamente nos dias de lua cheia e nova (sizígia) (CUNHA et al., 2013). Adicionalmente, devido ao efeito de represamento hidráulico promovido pelo rio Amazonas, durante a maré enchente o nível da coluna d'água do manancial tende a subir ainda mais, promovendo maior área de alagamento dentro das margens e da floresta de várzea. Naturalmente, esses processos típicos da região são essenciais para a manutenção da qualidade ambiental, social e econômica do estuário do rio Matapi, pois favorecem a troca de nutrientes, matéria orgânica e energia entre os ecossistemas (GALLO et al., 2005; REBOUÇAS et al., 2006; WARD et al., 2015; WARD et al., 2016; ABREU et al., 2020).

Assim como no caso do rio Matapi, Souza et al. (2009), pesquisando a influência de aspectos climáticos sobre corpos d'água da Amazônia Oriental, também observaram sinais de ocorrência do fenômeno El Niño ao longo de diversos estudos desenvolvidos a partir da década de 90, sendo mais significativos no oeste e centro do Pará e no litoral do Amapá. Oliveira et al. (2010) e Cunha et al. (2018) analisaram processos evaporativos na Bacia Hidrográfica do Rio Araguari (BHRA), contígua à BHRM, também no Amapá, mostrando significativas variações espaço-sazonais da evapotranspiração real (ETR) e evaporação (EV), respectivamente, representando o processo simultâneo de perda de água para a atmosfera por transpiração vegetal e por evaporação da superfície de água livre. Os referidos autores concluíram que, ao longo do ano analisado (2015), foi observada uma tendência de ocorrência de menores valores da ETR na região Norte do Amapá (1.200 a $1.250 \mathrm{~mm}$ ), aumentando na direção Sul, com os maiores valores ocorrendo na região Sudeste (1.400 a $1.450 \mathrm{~mm})$.

A análise de Oliveira et al. (2010) demonstra que se a média da precipitação anual no estado do Amapá se mantiver em $\approx 2.230 \mathrm{~mm}$, então normalmente mais de $1 / 3$ da precipitação ( $\approx 36 \%)$ seria 
evapotranspirada anualmente. Todavia, segundo Souza et al. (2009), se o período climático for atípico, com El Niño forte, semelhantemente ao que ocorreu na bacia do rio Matapi em 2015, a tendência é que a ETR aumente na mesma proporção, reduzindo as precipitações em até $40 \%$ ou mais e diminuindo potencialmente as recargas subterrâneas, a umidade do solo e as vazões dos canais naturais, independentemente dos refluxos das marés, que tendem a amenizar este processo na região estuarina (CUNHA et al., 2011; CUNHA et al., 2014). Por outro lado, as marés no rio Amazonas também demonstram sofrer esta influência negativa, pois em toda sua bacia o fenômeno El Niño tem reduzido significativamente as vazões em estuários (WILLIAMS et al., 2005; WARD et al., 2015; WARD et al., 2016), o que provavelmente também tem afetado o nível da coluna d’água no rio Matapi.

Segundo Abreu et al. (2015) e Abreu et al. (2020), o impacto imediato da baixa precipitação em bacias hidrográficas pode ser observado nas descargas líquidas dos rios drenantes, que tendem a mudar seus padrões de escoamento e a reduzir seus fluxos em relação aos anos considerados climatologicamente normais, resultando em menor recarga hidráulica do lençol freático (GUEDES et al., 2013) e em elevadas taxas de evapotranspiração nos períodos mais secos, principalmente em bacias mais antropizadas (OLIVEIRA et al., 2010; ROCHA et al., 2014; CUNHA et al., 2018). Todavia, a magnitude da redução da vazão fluvial também depende de fatores humanos associados, como o desmatamento, que contribui para a alteração do ciclo hidrológico mediante a diminuição da evapotranspiração e do escoamento superficial, que se eleva, uma vez que o solo exposto reduz a quantidade de água infiltrada (SENA et al., 2012).

De acordo com Gallo et al. (2005), Cunha et al. (2012) e Pereira et al. (2014), a compreensão das variações espaciais nos estuários provocadas pelas marés é fundamental. Como as oscilações sazonais da vazão fluvial implicam diretamente no volume de um corpo d'água, descargas hídricas mais ou menos intensas associadas a variações da maré podem interferir nas condições ambientais e sociais das bacias hidrográficas como, por exemplo, na capacidade dos rios de diluírem efluentes domésticos e industriais (DAMASCENO et al., 2015). Ricciardone et al. (2011) esclarecem que a autodepuração ocorre por intermédio de mecanismos essencialmente naturais, sendo diretamente dependente da turbulência ocasionada ao escoamento (reaeração atmosférica, que contribui para a promoção da difusão molecular nos processos biogeoquímicos das bacias), associada à vazão hídrica (ROVERSI et al., 2016; ABREU et al., 2020).

Nesse sentido, ao simularem um cenário típico de dispersão de efluentes no rio Matapi, Cunha et al. (2011) mostraram que conforme a dinâmica de inversão da maré se desenvolvia, poderia ocorrer a retenção hidráulica das plumas de efluentes próximas às suas respectivas fontes geradoras, dificultando a dispersão. Isso porque, mantendo-se inalterada uma fonte poluente em ambientes sujeitos a oscilações de maré, há a tendência de aumento da concentração de poluentes na lâmina d'água e nos sedimentos do estuário, principalmente no período seco, situação capaz de promover desequilíbrios nas comunidades biológicas e de causar consequências sanitárias devido a alterações na qualidade da água (AMARAL et al., 2003; OLIVEIRA et al., 2014; MONTEIRO et al., 2015; SILVA et al., 2015; SANT'ANA et al., 2019). Por outro lado, de acordo com Cunha et al. (2013), como a baixa pluviosidade favorece a redução do nível máximo que as colunas d'água dos rios amazônicos podem atingir normalmente, a conexão e o consequente fluxo de matéria e energia 
entre os ambientes aquático e terrestre alagável tendem a ficar prejudicados, bem como a velocidade e a turbulência da água.

\section{CONCLUSÕES}

Parâmetros hidrodinâmicos são elementos-chave em análises de gerenciamento de recursos hídricos, especialmente em estudos de ambientes estuarinos amazônicos, sem os quais não é possível quantificar suas variações espaço-sazonais associadas a aspectos de qualidade da água. Nesse sentido, os resultados das análises comparativas hidroclimáticas de curto prazo no padrão hidrodinâmico do rio Matapi confirmaram o efeito do fenômeno El Niño na redução dos índices de precipitação locais em 2015, bem como na diminuição das vazões medidas. Adicionalmente, os parâmetros hidrodinâmicos mostraram-se diretamente dependentes das oscilações do rio Amazonas, contudo, modulados por efeitos da precipitação na bacia $(p<0,05)$, variando de acordo com o período sazonal. Quando comparados os resultados deste trabalho com os dados de outros estudos semelhantes (ano de 2015 versus 2001, 2005 e 2006), foi observada sensível variação espacial e influência de marés de sizígia no rio Matapi, sugerindo comprometimento de características físicas e ecológicas naturais do escoamento, com a redução de praticamente todos os parâmetros medidos, especialmente da amplitude do nível de maré, da vazão e da velocidade, bem como alterações do tempo de enchente e vazante.

Os impactos de eventos hidroclimáticas extremos de curto prazo sobre o padrão hidrodinâmico do rio Matapi podem ser considerados como indicadores locais de avaliação da qualidade ambiental de ecossistemas aquáticos de várzea estuarina na Amazônia. No longo prazo, mantida a frequência de eventos climáticos adversos (SORRIBAS et al., 2016; SANTOS et al., 2018; CUNHA et al., 2018), poderão ser observados efeitos irreversíveis para os ecossistemas e as atividades antrópicas locais. Portanto, a compreensão precisa dos efeitos hidroclimáticos sobre a hidrodinâmica de ambientes estuarinos na região amazônica demonstra ser fundamental para o alcance do desenvolvimento sustentável.

\section{REFERÊNCIAS}

ABREU, C. H. M.; BRITO, D. C; BARROS, M. L. C.; TEIXEIRA, M. R.; CUNHA, A. C.. Hydrodynamic modeling and simulation of water residence time in the estuary of the lower amazon river. Water, v.12, p.1-30, 2020.

ABREU, C. H. M.; CUNHA, A. C.. Qualidade da água em ecossistemas aquáticos tropicais sob impactos ambientais no baixo rio Jari/AP: revisão descritiva. Biota Amazônia, v.5, n.2, p.119-131, 2015. DOI: http://doi.org/10.18561/21795746/biotaamazonia.v5n2p119-131

ANA. Agência Nacional de Águas. Sistema Hidro: telemetria. ANA, 2016.

ALCÂNTARA, E. H.. Análise unidimensional dos processos de mistura estuarina do rio Periá, MA (Brasil). Caminhos de Geografia, v.7, n.20, p.46-57, 2007.

AMARAL, L. A.; NADER FILHO, A.; ROSSI JUNIOR, O. D.; FERREIRA, F. L. A.; BARROS, L. S. S.. Água de consumo humano como fator de risco à saúde em propriedades rurais. Revista de Saúde Pública, v.37, n.4, p.510-514, 2003. DOI: http://doi.org/10.1590/S0034-89102003000400017

CONAMA. Conselho Nacional do Meio Ambiente. Resolução $n^{\circ}$ 357. Dispõe sobre a classificação dos corpos de água e diretrizes ambientais para o seu enquadramento, bem como estabelece as condições e padrões de lançamento de efluentes, e dá outras providências. Brasília: CONAMA, 2005.

CUNHA, A. C.; CUNHA, H. F. A.; BRASIL JÚNIOR, A. C. P. B.; DANIEL, L. A.; SCHULZ, H. E.. Qualidade microbiológica da água em rios de áreas urbanas e periurbanas no baixo Amazonas: o caso do Amapá. Revista Engenharia Sanitária e Ambiental, v.9, n.4, p.322-328, 2004. DOI: http://doi.org/10.1590/S1413-41522004000400009

CUNHA, A. C.; BRITO, D. C.; BRASIL JUNIOR, A. C.; PINHEIRO, L. A. R.; CUNHA, H. F. A.; KRUSCHE, A. V.. Challenges and solutions for hydrodynamic and water quality in rivers in the 
amazon basin. In: SCHULZ, H. E.; SIMÕES, A. L. A.; LOBOSCO, R. J.. Hydrodinamics: natural water bodies. Zagrebe, 2012.

CUNHA, A. C.; NAZARÉ, A. S.; PANTOJA, S.; CUNHA, H. F. A.. Monitoramento de águas superficiais em rios estuarinos do estado do Amapá sob poluição microbiológica. Boletim Museu Paraense Emílio Goeldi, v.1, n.1, p.141-148, 2003.

CUNHA, A. C.; PINHEIRO, L. A. R.; CUNHA, H. F. A.; SCHULZ, H. E.; BRASIL JUNIOR, A. C. P.; SOUZA, E. B.. Simulação da hidrodinâmica e dispersão de poluentes com monitoramento virtual no rio Matapi/AP. Revista de Estudos Ambientais, v.13, n.2, p.18-32, 2011. DOI: http://doi.org/10.7867/1983-1501.2011v13n2p18-32

CUNHA, A. C.; SANTOS, E. W. G.; SANTOS, E.; GUEDES, M. C.; OLIVEIRA, G. P.; BLANCO, C. J. C.; ROSMAN, P. C. C.. Importância da hidrodinâmica na dispersão de sementes em sistemas florestais do Baixo Estuário Amazônico. In: SIMPÓSIO BRASILEIRO DE AGROPECUÁRIA SUSTENTÁVEL E CONGRESSO INTERNACIONAL DE AGROPECUÁRIA SUSTENTÁVEL. Anais. Viçosa: UFV, 2013.

CUNHA, A. C.; STERNBERG, L. S. L.. Using stable isotopes 180 and $2 \mathrm{H}$ of lake water and biogeochemical analysis to identify factors affecting water quality in four estuarine Amazonian shallow lakes. Hydrological Processes, v.32, p.1188-1201, 2018. DOI: http://doi.org/10.1002/hyp.11462

CUNHA, A. C.; VILHENA, J. E. S.; SANTOS, E.; SARAIVA J. B.; KUHN, P. A. F.; BRITO, D. C.; SOUZA, E. B.; ROCHA, E. P.; CUNHA, H. F. A.; BRITO, A. U.; BRASIL JUNIOR, A. C. P.; PACA, V.H.; SANTOS, P. V. C. J.. Evento extremo de chuvavazão na bacia hidrográfica do rio Araguari, Amapá, Brasil. Revista Brasileira de Meteorologia, v.29, p.95-110, 2014. DOI: http://doi.org/10.1590/0102-778620130051

DAMASCENO, M. C. S.; RIBEIRO, H. M. C.; TAKIYAMA, L. R.; PAULA, M. T.. Avaliação sazonal da qualidade das águas superficiais do rio Amazonas na orla da cidade de Macapá, Amapá, Brasil. Revista Ambiente e Água, v.10, n.3, p.598613, 2015.

EMBRAPA. Empresa Brasileira de Pesquisa Agropecuária. Degradação florestal na Amazônia: como ultrapassar os limites conceituais, científicos e técnicos para mudar esse cenário. Belém: EMBRAPA, 2015.

FERREIRA-FERREIRA, J.; SILVA, T. S. F.; STREHER, A. S.; AFFONSO, A. G.; FURTADO, L. F.; FORSBERG, B. R.; VALSECCHI, J.; QUEIROZ, H. L.; NOVO, E. M. L. M.. Combining ALOS/PALSAR derived vegetation structure and inundation patterns to characterize major vegetation types in the Mamirauá Sustainable Development Reserve, Central Amazon floodplain, Brazil. Wetlands Ecol Manage, n.23, p.41-59, 2014. DOI: http://doi.org/10.1007/s11273$\underline{014-9359-1}$

FAO. Food and Agriculture Organization of the United Nations. 2015-2016 El Niño: early action and response for agriculture, food security and nutrition. Rome, 2016.

FRIEDRICHS, C. T.. Barotropic tides in channelized estuaries. Cambridge: Cambridge University Press, 2010.

GALLO, M. N.; VINZON, S. B.. Generation of overtides and compound tides in Amazon estuary. Ocean Dinamics, v.55, p.441-448, 2005.

GLANTZ, M. H.. Shades of chaos: lessons learned about lessons learned about forecasting El Niño and its impacts. International Journal of Disaster Risk Science, v.6, p.94 103, 2015.

GODIN, G.. Frictional effects in river tides. New York: John Wiley \& Sons, 1991.

GONZALEZ, R. A.; ANDREOLIZ, R. V.; CÂNDIDO, L. A.; KAYANO, M. T.; SOUZA, R. A. F.. A influência do evento EI Niño - oscilação Sul e Atlântico Equatorial na precipitação sobre as regiões norte e nordeste da América do Sul. Acta Amazonica, v.43, n.4, p.469-480, 2013. DOI: http://doi.org/10.1590/S0044-59672013000400009

GUEDES, A. E. D. S.; CÂNDIDO, L. A.; SANTOS, A. R. S. E.. Variabilidade do estoque de água continental e sua relação com as cheias e vazantes extremas na Amazônia. Revista Ambiente e Água, v.8, n.2, p.88-99, 2013. DOI: http://doi.org/10.4136/ambi-agua.1137

IMADA, K. S.; ARAÚJO, T. S.; MUNIZL, P. T.; PÁDUA, V. L.. Fatores socioeconômicos, higiênicos e de saneamento na redução de diarreia na Amazônia. Revista Saúde Pública, v.50, n.77, p.1-11, 2016

INPE. Instituto Nacional de Pesquisas Espaciais. Ministério da Ciência, Tecnologia, Inovações e Comunicações. INPE, 2016.

KJERFVE, B.; WOLAVER, T. G.. Sampling optimization for studies of tidal transport in estuaries. In: AMERICAN FISHERIES SOCIETY SYMPOSIUM. Anais. 1988.

KJERFVE, B.; PROEHL, J. A.; SCHWING, F. B.; SEIM, H. E.; MAROZAS, M.. Temporal and spatial considerations in measuring estuarine water fluxes. New York: Academic Press, 1982.

LATHUILLIERE, M. J.; BULLE, C.; JOHNSON, M. S.. Complementarity in mid-point impacts for water use in life cycle assessment applied to cropland and cattle production in Southern Amazônia. Journal of Cleaner Production, v.219, p.497-507, 2019. DOI: http://doi.org/10.1016/j.jclepro.2019.02.021

LOBÓN-CERVIA, J.; HESS, L. L.; MELACK, J. M.. The association between forest cover and fish abundance on the Amazon floodplain. Hydrobiologia, v.250, p.245-255, 2015.

MAO, Q.; SHI, P.; YIN, K.; GAN, J.; QI, Y.. Tides and tidal currents in Pearl River Estuary. Continental Shelf Research, v.24, p.1797-1808, 2004. DOI: http://doi.org/10.1016/j.csr.2004.06.008

MIRANDA, L. B.; CASTRO, B. M.; KJERFVE, B.. Princípios de oceanografia física de estuários. São Paulo: Edusp, 2002.

MONTEIRO, S. M.; EL-ROBRINE, M.; ALVES, I. C. C.. Dinâmica sazonal de nutrientes em estuário amazônico. Mercator, v.14, n.1, p.151-162, 2015.

MOREIRA, S. F.; CONCEIÇÃO, C. S.; CRUZA, M. C. S.; PEREIRA JÚNIOR, A.. A influência dos fenômenos El Niño e La Niña sobre a dinâmica climática da região Amazônica. 
Multidisciplinary Reviews, p.1-8, 2018. DOI:

http://doi.org/10.29327/multi.2018014

NICOLITE, M.; TRUCCOLO, E. C.; SCHETTINI, C. A. F.; CARVALHO, C. E. V.. Oscilação do nível de água e a cooscilação da maré astronômica no baixo estuário do rio Paraíba do Sul, RJ. Revista Brasileira de Geofísica, v.27, n.2, p.225-239, 2009.

NUNES FILHO, J. R.. Modelagem da inundação de florestas de várzea do Estuário Amazônico. Dissertação (Mestrado) Fundação Universidade Federal do Amapá, Macapá, 2016.

OLIVEIRA, B. S. S.; CUNHA, A. C.. Correlação entre a qualidade da água e variabilidade da precipitação no sul do estado do Amapá. Revista Ambiente e Água, v.9, n.2, p.261275, 2014

OLIVEIRA, L. L.; CUNHA, A. C.; JESUS, E. S.; BARRETO, N. J. C. Características hidroclimáticas da Bacia do Rio Araguari. In: CUNHA, A. C.; SOUZA, E. B.; Cunha, H. F. A.. Tempo, clima e recursos hídricos: resultados do Projeto REMETAP no estado do Amapá. Macapá: IEPA, 2010.

PARKER, B. B.. The relative importance of the various nonlinear mechanisms in a wide range of tidal interactions (review). In: APRKER, B. B.. Tidal hydrodynamics. New York: John Wiley \& Sons, 1991.

PEREIRA, N. N.; BOTTER, R. C.; FOLENA, R. D.; PEREIRA, J. P. F. N.; CUNHA, A. C.. Ballast water: a threat to the Amazon Basin. Marine Pollution Bulletin, v.84, n.1-2, p.330-338, 2014. DOI: http://doi.org/10.1016/j.marpolbul.2014.03.053

PUGH, D. T.. Changing sea levels: effects of tides, weather, and climate. Cambridge: Cambridge University Press, 2004.

REBOUÇAS, A. C.; BRAGA, B.; TUNDISI, J. G.. Águas doces no Brasil: capital ecológico, uso e conservação. São Paulo: Escritura, 2006

RICCIARDONE, P.; PEREIRA, O. S.; PEREIRA, C. S.. Avaliação da capacidade de autodepuração do rio das Mortes no município de Vassouras/RJ. Revista Eletrônica TECCEN, v.4, n.3, p.63-76, 2011. DOI:

http://doi.org/10.21727/teccen.v4i3.491

ROCHA, V. M.; CORREIRA, F. W. S.; FONSECA, P. A. M.. Reciclagem e precipitação na Amazônia: um estudo de revisão. Revista Brasileira de Meteorologia, v.30, n.1, p.5970, 2014. DOI: http://doi.org/10.1590/0102-778620140049

ROVERSI, F.; ROSMAN, P. C. C.; HARARI, J.. Análise da renovação das águas do Sistema Estuarino de Santos usando modelagem computacional. Revista Ambiente e Água, v.11, n.3, p.566-585, 2016.

SALAME, C. W.; QUEIROZ, J. C. B.; SOUZA, E. B.; FARIAS, V. J. C.; ROCHA, E. J. P.; MOURA, H. P.. Um estudo comparativo dos modelos Box-Jenkins e Redes Neurais Artificiais na previsão de vazões e precipitações pluviométricas da Bacia Araguaia, Tocantins, Brasil. Revista Brasileira de Ciências Ambientais, n.52, p.28-43, 2019. DOI: http://doi.org/10.5327//Z2176-947820190444

SANT'ANA, A. C.; VITAL, M. J. S.; SILVA, H. E. B.. Influência da urbanização na qualidade da água do rio Branco e afluentes no município de Boa Vista, Roraima, Amazônia brasileira. Revista Gestão de Águas da América Latina, v.16, p.1-9, 2019.

SANTOS, P. V. C. J.; CUNHA, A. C.. Potencial de vazão ambiental: método participativo para estimar vazão ambiental em rios na Amazônia. Revista Engenharia Sanitária e Ambiental, v.23, n.1, p.137-150, 2018. DOI: http://doi.org/10.1590/s1413-41522018140637

SANTOS, E. S.; CUNHA, A. C.; CUNHA, E. D. S.. Análise espaço-sazonal da qualidade da água na Zona FlúvioMarinha do rio Araguari-Amazônia oriental-Brasil. Revista Brasileira de Recursos Hídricos, v.19, n.3, p.215-226, 2014.

SANTOS, I.; FILL, H. D.; SUGAI, M. R. B.; KISHI, R. T.; MARONE, E.; LAUTERT, L. F.. Hidrometria aplicada. Curitiba: Instituto de Tecnologia para o Desenvolvimento, 2001.

SENA, J. A.; DEUS, L. A. B.; FREITAS, M. A. V.; COSTA, L. Extreme events of droughts and floods in Amazônia: 2005 and 2009. Water Resour Manage, v.26, p.1665-1676, 2012. DOI: http://doi.org/10.1007/s11269-012-9978-3

SERRÃO, E. A. O.; SANTOS, C. A.; WANZELER, R. T. S.; GONÇALVES, L. J. M.; LIMA, A. M. M.. Avaliação da seca de 2005 e 2010 na Amazônia: análise da Bacia Hidrográfica do Rio Solimões. Revista Geografia Acadêmica, v.9, n.2, p.5-20, 2015. DOI: http://doi.org/10.18227/1678-7226rga.v9i2.2945

SILVA, B. M. B.; SILVA, D. D.; MOREIRA, M. C.. Influência da sazonalidade das vazões nos critérios de outorga de uso da água: estudo de caso da bacia do rio Paraopeba. Revista Ambiente e Água, v.10, n.3, p.623-634, 2015.

SILVA, S. H.; NODA, S. N.. A dinâmica entre as águas e terras na Amazônia e seus efeitos sobre as várzeas. Revista Ambiente e Água, v.11, n.2, p.377-386, 2016. DOI: http://doi.org/10.4136/ambi-agua.1805

SORRIBAS, M. V.; PAIVA, R. C. D.; MELACK, J. M.; BRAVO, J. M.; JONES, C.; CARVALHO, L.; BEIGHLEY, E.; FORSBERG, M. H. C.. Projections of climate change effects on discharge and inundation in the Amazon basin. Climatic Change, v.136, p.555-570, 2016.

SOUZA JUNIOR, C. M.; PEREIRA, K.; LINS, V.; HAIASHY, S.; SOUZA, D.. Web-oriented GIS system for monitoring, conservation and law enforcement of the brazilian Amazon. Earth Science Informatics, v.2, n.205, p.205-215, 2009.

SOUZA, E. B.; LOPES, M. N.G.; ROCHA, E. J. P.; SOUZA, J. R. S.; CUNHA, A. C.; SILVA, R. R.; FERREIRA, D. B. S.; SANTOS, D. M.; CARMO, A. M. C.; SOUSA, J. R. A.; GUIMARÃES, P. L.; MOTA, M. A. S.; MAKINO, M.; SENNA, R. C.; SOUSA, A. M. L.; MOTA, G. V.; KUHN, P. A. F.; SOUZA, P. F. S.; VITORINO, M. I.. Precipitação sazonal sobre a Amazônia oriental no período chuvoso: observações e simulações regionais com o RegCM3. Revista Brasileira de Meteorologia, v.24, n.2, p.111-124, 2009. DOI: http://doi.org/10.1590/S010277862009000200001

SOUZA, L. J. A.. Variação espaço-sazonal da qualidade da água: subsídio à criação de peixes em tanques-rede no baixo Matapi/AP. Dissertação (Mestrado em Biodiversidade Tropical) - Fundação Universidade Federal do Amapá, Macapá, 2016. 
TAKIYAMA, L. R.; CUNHA, A. C.; SILVA, M. S.; MARTINS, M. H. A.; RODRIGUES, L. J. C.; AVELAR, S. B.; DIAS, R.. Subsídios à gestão de recursos hídricos na bacia hidrográfica do rio Matapi. Relatório Técnico Final. Processo CNPq no. 504083/2003-1. Macapá: IEPA/GERCO-AP, 2007.

TORRES, A. M.; EL-ROBRINI, M.. Amapá. In: MUEHE, D.. Erosão e progradação do litoral brasileiro. Brasília: MMA, 2006.

WARD, N. D.; BIANCHI, T. S.; SAWAKUCHI, H. O.; GAGNEMAYNARD, W.; CUNHA, A. C.; BRITO, D. C.; NEU, V.; VALERIO, A. M.; SILVA, R.; KRUSCHE, A. V.; RICHEY, J. E.; KEIL, R. G.. The reactivity of plant-derived organic matter and the potential importance of priming effects along the lower Amazon river. Journal of Geophysical Research, v.121, p.1522-1539, 2016. DOI: http://doi.org/10.1002/2016JG003342
WARD, N. D.; KEIL, R. G.; MEDEIROS, P. M.; BRITO, D. C.; CUNHA, A. C.; DITTMAR, T.; YAGER, P. L.; KRUSCHE, A. V.; RICHEY, J. E.. Degradation of terrestrially derived macromolecules in the Amazon river. Nature Geoscience, v.6, p.530-533, 2013.

WARD, N. D.; KRUSCHE, A. V.; SAWAKUCHI, H. O.; BRITO, D. C.; CUNHA, A. C.; MOURA, J. M. S.; SILVA, R.; YAGER, P. L.; KEIL, R. G.; RICHEY, J. E.. The compositional evolution of dissolved and particulate organic matter along the lower Amazon River-Óbidos to the ocean. Marine Chemistry, v.177, p.244-256, 2015. DOI: http://doi.org/10.1016/j.marchem.2015.06.013

WILLIAMS, E.; DALL' ANTONIA, A.; DALL' ANTONIA, V.; ALMEIDA, J. M.; SUAREZ, F.; LIEBMANN, B.; MAHADO, A. C. M.. The drought of the century in the Amazon basin: an analysis of the regional variation of rainfall in South America in 1926. Acta Amazonica, v.35, n.2, p.231-238, 2005. DOI: http://doi.org/10.1590/S0044-59672005000200013

A CBPC - Companhia Brasileira de Produção Científica (CNPJ: 11.221.422/0001-03) detém os direitos materiais desta publicação. Os direitos referem-se à publicação do trabalho em qualquer parte do mundo, incluindo os direitos às renovações, expansões e disseminações da contribuição, bem como outros direitos subsidiários. Todos os trabalhos publicados eletronicamente poderão posteriormente ser publicados em coletâneas impressas sob coordenação da Sustenere Publishing, da Companhia Brasileira de Produção Científica e seus parceiros autorizados. Os (as) autores (as) preservam os direitos autorais, mas não têm permissão para a publicação da contribuição em outro meio, impresso ou digital, em português ou em tradução. 